\title{
Effect of various heat treatments to target apple leafcurling midge (Dasineura mali) cocoons on apples
}

\author{
Natalie E.M. Page-Weir*, Lisa E. Jamieson, Amanada J. Hawthorne, Reuben T. \\ Wilkinson, Dominic E. Hartnett, Simon P. Redpath, Asha Chhagan, Alan B. Woolf, \\ and Lindy F. Guo \\ The New Zealand Institute for Plant \& Food Research Limited (PFR), Private Bag 92169, \\ Auckland Mail Centre, Auckland, 1142, New Zealand \\ *Corresponding author: Natalie.Page@plantandfood.co.nz
}

\begin{abstract}
New Zealand apples infested with apple leafcurling midge (ALCM) cocoons are a quarantine issue for growers exporting to many markets. The presence of ALCM on apples in these markets requires fumigation with methyl bromide, which decreases fruit quality. The effectiveness of various forms of heat treatments on ALCM were evaluated as alternatives. Apples infested with ALCM cocoons were subjected to one of the following heat treatments: Controlled Atmosphere Temperature Treatment System (CATTS; $1 \% \mathrm{O}_{2}, 15 \% \mathrm{CO}_{2}, 46^{\circ} \mathrm{C}, 3$ h), hot air $\left(46^{\circ} \mathrm{C}, 3 \mathrm{~h}\right.$ ), hot water high pressure washing (hot-HPW; $55^{\circ} \mathrm{C}, 100 \mathrm{psi}, 15-20 \mathrm{~s}$ ), or hot water drench (HWD; $55^{\circ} \mathrm{C}, 40 \mathrm{psi}, 15-20 \mathrm{~s}$ ). ALCM removal and mortality were assessed 7-days post-treatment. The hot-air and CATTS treatments provided the greatest control, with 82.2 and $92.2 \%$ mortality respectively. More cocoons were removed with hot-HPW (46.6\%) compared with ambient-HPW (27.1\%). Neither HWD nor hot-HPW increased mortality of cocooned ALCM over that in untreated controls. ALCM cocoons are particularly difficult pests to remove/kill; further research should focus on incorporating multiple control measures into the current systems approach.
\end{abstract}

Keywords Apple leafcurling midge, controlled atmosphere temperature treatment, hot high pressure washing, hot water drench.

\section{INTRODUCTION}

Apple leafcurling midge (ALCM, Dasineura mali, Kieffer; Diptera Cecidomyiidae) is a pest of apple crops in New Zealand and other countries with cool-temperate regions (e.g. the UK, northern Europe and Canada). After mating, females oviposit in young leaf shoots. The larvae feed upon the upper surface of the leaves, distorting leaf growth and preventing leaves from unfurling, causing the edges to form tight, red-tinged curls. Mature midge larvae exit their protective leaf-roll, often triggered by rainfall, and fall to the ground, with the majority pupating in the soil within a silken cocoon. However, a small proportion of larvae fall onto fruit and spin their cocoon in either the stem or calyx region of the apple (Lowe 1993).

New Zealand apples infested with ALCM cocoons are a quarantine issue for growers exporting fruit to many markets including Australia, Japan, China and Taiwan. The presence of ALCM on apples destined for these markets requires fumigation with methyl bromide to be undertaken prior to export, and this process can decrease fruit quality (Drake et al. 1988).

High-pressure water washing (HPW) is used commercially in New Zealand for apples and avocados to remove of pests (including ALCM) from export fruit before packing (Jamieson et al. 2010). The standard system involves a moderately high pressure, high-volume ambienttemperature water system that washes the 
apples for 10-20 seconds using multiple nozzles while the fruit move over rotating brushes. This procedure is based on overseas systems that were developed for removal of pests from citrus and apples (Honiball et al. 1979; Walker et al. 1996, 1999) and is known as a Honiball washer. However, a well-set-up standard Honiball apple washer typically removes, at best, about 50\% of ALCM cocoons (DJ Rogers, HortResearch pers. comm.). A new apple-washer system using individual cups and a unique rotary-wand system was developed by Compac ${ }^{\oplus}$ Sorting Equipment in 2009. This system has been found to remove $85-95 \%$ of ALCM cocoons (DJ Rogers, HortResearch pers. comm.; AB Woolf unpublished data) but even higher levels of removal are required to gain access into overseas markets. Treatments to enhance the removal of ALCM cocoons with HPW (Honiball washer) have included the application of pre-HPW dips. However, these dips were not found to be particularly successful, with the highest removal of $66 \%$ (a 25\% increase over HPW alone) using a hot-water pre-treatment dip (Page-Weir et al. 2017).

The Controlled Atmosphere Temperature Treatment System (CATTS) was first described by Neven \& Mitcham (1996) as a novel tool for postharvest disinfestation of fresh agricultural produce. That study demonstrated the potential effectiveness of the treatment, which combined heat $\left(45\right.$ or $\left.47^{\circ} \mathrm{C}\right)$ with a controlled atmosphere (CA) of $1 \%$ oxygen $\left(\mathrm{O}_{2}\right)$ and $15 \%$ carbon dioxide $\left(\mathrm{CO}_{2}\right)$, to control codling moth (Cydia pomonella) in sweet cherries. CATTS treatments targeting codling moth have also been developed for peaches and nectarines using a target temperature of $46^{\circ} \mathrm{C}$ and a controlled atmosphere of $1 \% \mathrm{O}_{2}$ and $15 \% \mathrm{CO}_{2}$ (Neven et al. 2006), and for apples using a target temperature of $46^{\circ} \mathrm{C}$ in a controlled atmosphere of $<1 \% \mathrm{O}_{2}$ and $15 \% \mathrm{CO}_{2}$ (Neven \& Rehfield-Ray 2006).

Studies of fruit quality following CATTS treatments have shown the commodities tested were not adversely affected and all market standards were met (Neven 2005; Neven \& Drake 1996; Neven et al. 2001; Shellie et al. 2001).
The research reported here focused on assessing any enhanced mortality and/or removal of ALCM using a range of heat treatments: CATTS; hot high pressure washing; or a hotwater drench.

\section{MATERIALS AND METHODS Establishment of apple leafcurling midge on fruit}

Leaves infested with ALCM were collected from a range of organic and commercially managed orchards in Havelock North and Nelson and placed in separate plastic collection bags from each site. There were 2-6 bags per site. Bags of infested leaves were sent to Plant $\&$ Food Research (PFR), Auckland, where they were held at $20^{\circ} \mathrm{C}$, 16:8 h (light:dark) for approximately one week until the mature ALCM larvae had exited the leaf rolls. These larvae were then removed from the collection bags and established as cocoons onto 'Scifresh'/Jazz ${ }^{\text {Tw }}$ or 'Royal Gala' apples using the method of Hawthorne et al. (2016). Large numbers of infested fruit were required for this study so, for cocoon establishment, the apples were placed into an apple box for storage at $7^{\circ} \mathrm{C}$ until treatment, approximately 2-6 months later when the required number of fruit had been collected.

\section{Treatments}

The day before treatment, ALCM-infested apples were randomly selected from across the 2-6 month storage range, removed from $7^{\circ} \mathrm{C}$ and placed at $20^{\circ} \mathrm{C}$. The following day, these apples were divided into one of seven treatments (Table 1). Treatments were applied from 19 to 21 June 2017, with a single replicate of between 35 and 51 fruit per treatment applied on each day. Each treatment was replicated three times.

\section{Controlled Atmosphere Temperature Treatment System (CATTS)}

CATTS treatments were applied within a purposebuilt treatment system at PFR (see Jamieson et al. 2018 for a more completed description of this equipment). The internal treatment chamber of the CATTS unit consisted of two columns of four 
Table 1 Heat treatments applied to apple leafcurling midge (ALCM)-infested apples.

\begin{tabular}{lcc}
\hline Treatment & Treatment time & $\begin{array}{c}\text { Total number of } \\
\text { infested fruit treated }\end{array}$ \\
\hline Untreated control & N/A & 121 \\
Controlled atmosphere temperature treatment system & $3 \mathrm{~h}$ & 120 \\
$\left(\right.$ CATTS $\left.^{1}\right)$ & $3 \mathrm{~h}$ & 121 \\
Hot air $\left(46^{\circ} \mathrm{C}\right)$ only $(\mathrm{CATTS}$ control $)$ & $15-20 \mathrm{~s}$ & 120 \\
Hot water $\left(55^{\circ} \mathrm{C}\right) /$ high pressure washing & $15-20 \mathrm{~s}$ & 120 \\
Ambient temperature $\left(\sim 20^{\circ} \mathrm{C}\right)$ water $/$ high pressure & $15-20 \mathrm{~s}$ & 120 \\
washing (industry standard) & $15-20 \mathrm{~s}$ & 120 \\
Hot-water drench $\left(55^{\circ} \mathrm{C}\right)$ & & \\
Ambient-temperature water drench $\left(\sim 20^{\circ} \mathrm{C}\right)$ & &
\end{tabular}

${ }^{1}$ CATTS treatment: $1 \% \mathrm{O}_{2}, 15 \% \mathrm{CO}_{2}, 46^{\circ} \mathrm{C}$.

baskets. Temperature probes that ran through the main chamber door were placed within, or around, fruit before sealing the chamber.

Gases (e.g. $\mathrm{CO}_{2}$ and/or nitrogen $\mathrm{N}_{2}$ ) were plumbed in through ports on the outer side of the chamber. The inside of the chamber was fitted with heating elements, a humidifier and a fan capable of running at air speeds of $1.3 \mathrm{~m} / \mathrm{s}$. Air-direction gates allowed for air direction to be changed during treatment mitigating any "cold spots" within the treatment chamber.

Each day, 5-7 infested apples were loaded into each of the eight baskets. Filler fruit (unsprayed 'Fuji') were placed around the infested apples in each basket to ensure equal fruit loading in all runs. Treatments were applied for 3 hours after the establishment of the required atmosphere $\left(1 \% \mathrm{O}_{2}, 15 \% \mathrm{CO}_{2}\right)$. Atmosphere establishment was achieved by introducing $\mathrm{N}_{2}$ into the chamber to lower the $\mathrm{O}_{2}$, at which point $\mathrm{CO}_{2}$ was introduced until the target concentrations were reached. Treatment began when the temperature ramp began. A temperature ramp of $12^{\circ} \mathrm{C} / \mathrm{h}$ from $23-46^{\circ} \mathrm{C}$ was used; therefore treatment included a 1.92 -h ramp time and a 1.08 -h hold time. Hotair-only (CATTS control) fruit were treated in the unit with the same temperature ramp and hold time conditions but with the introduction of compressed air alone (i.e. without the controlled atmosphere conditions).

\section{Hot high pressure washing}

Both hot $\left(55^{\circ} \mathrm{C}\right)$ and ambient temperature HPW of apples was conducted on a Honiball system at PFR Auckland. This system consisted of a gantry of eight manifolds, each with five vertically mounted nozzles at a spacing of $160 \mathrm{~mm}$ over a bed of rotating brushes. The nozzles used were ProMax $^{\circledast}$ QuickJet $^{\circledR}$ Spray Tips (QPTA-15-40: Spraying Systems, Auckland, New Zealand) at a height of $150 \mathrm{~mm}$ from the top of a standardised 'apple' (measured using a tennis ball). The brush bed consisted of scalloped brushes, which moved the fruit to sit between the rollers, allowing the nozzles to target the fruit. The manifolds were aligned to the gaps between the brush rollers to reduce wear on the brushes. The treatment times of 15-20 s were achieved by fruit pushing other fruit through the system. An operating water pressure of 100 psi was selected based on the average pressure used by the apple industry for HPW. Water temperature was measured at the spray exit from the nozzle using a handheld Ebro ${ }^{\otimes}$ probe to confirm the desired water temperature was applied before passing fruit through the washer.

\section{Hot-water drench}

The hot-water drenching unit was custom built at PFR Auckland. Hot water was pumped from a reservoir using a Lowara 10HM03P15T5RVBE three-phase $(415 \mathrm{~V} 50 \mathrm{~Hz})$ water pump at 40 psi. 
Hot water was delivered to a gantry mounted over a rolling brush bed. The gantry incorporated six rows of three nozzles pointing straight down and offset from row to row. The nozzle type used for this trial was the, Pro Max ${ }^{\circledR}$ QPHA-10 cone nozzle (Spraying Systems, Auckland, New Zealand). Water temperature was measured at the nozzle using a hand-held Ebro probe to confirm the desired water temperature was applied before passing fruit through the drenching system. The hot-water drench system differed from the high pressure washing in respect to the pressure used (40 psi vs $100 \mathrm{psi}$ ), the angle of the nozzles, and the brush bed (straight vs scalloped brushes).

\section{ALCM mortality and removal assessment}

After treatments, infested apples were placed within fine mesh bags that were placed at $20^{\circ} \mathrm{C}$, 16:8 (light:dark), for 7 days prior to mortality assessment. This step was included to ensure that dead larvae had time to dry out and discolour, so as not to be incorrectly assessed as moribund. The location and number of any remaining cocoons was recorded during assessment. Fine pins were then used to tear open each cocoon carefully. The pupating larvae were then prodded and assessed for mortality: live = movement/ plump body; dead = no movement/dried and discoloured body; moribund = plump body but no movement.

Parasitised cocoons were included in the removal data; however, they were excluded from the mortality analysis as ALCM larvae were dead as a consequence of parasitism, not from heat treatment. No physical differences in the cocoons of parasitised and unparasitised ALCM were observed prior to treatment.

\section{Statistical analyses}

Data analysis was conducted in SAS version 9.4 (SAS Inc., USA). The removal rate (removal/total initally present) and mortalities (dead/total) were fitted to binomial models using Logistic regression (proc logistic) with specifying "scale = deviance" to adjust for over-dispersion.

A high number (12.5\%) of moribund larvae (plump, no movement when prodded, no development after 7 days) were observed so a weighting was applied to these. Concurrent work on ALCM emergence on larvae stored under the same regime as those used for this trial had on average a $10 \%$ emergence rate over 42 days (A. Hawthorne, unpublished data). Based on these other data, a weighting of $10 \%$ live was applied to the moribund total, with the remaining moribund larvae classified as dead (i.e. nonviable and would not develop).

\section{RESULTS}

\section{Cocoon removal}

There was no significant statistical difference (at the 5\% significance level) in the removal of ALCM cocoons from apples when passed through the drench system, either at ambient temperature $\left(20^{\circ} \mathrm{C}\right)$ or at $55^{\circ} \mathrm{C}$ (Fig. 1). There was a significant increase in removal of cocoons with hot water $\left(55^{\circ} \mathrm{C}\right) /$ high-pressure washing compared with ambient temperature water/highpressure washing ( $46.6 \%$ and $27.1 \%$ respectively; Fig. 1); however, this increase did not result in more than $50 \%$ removal of cocoons.

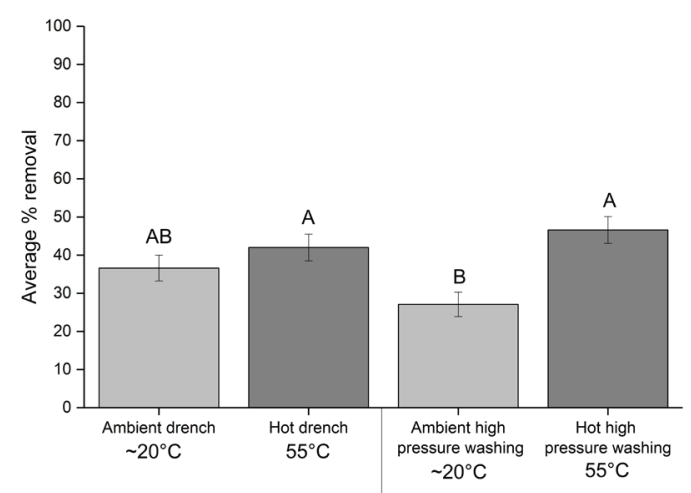

Figure 1 The average percentage removal of apple leafcurling midge (Dasineura mali) cocoons from apples with either a drench or high pressure washing. Vertical lines indicate the standard error of the means. Common letters above bars indicate no statistically significant difference among treatments. 


\section{Apple leafcurling midge mortality}

Use of the CATTS treatment led to the highest mortality of cocooned ALCM in this trial (93.7\%, Fig. 2). Hot-air treatment also provided a high degree of control (82.2\% mortality), and there was no statistical difference between these two treatments (at the 5\% significance level). Neither a hot-water drench nor hot-water/high pressure washing provided increased mortality compared with ambient water treatments or the untreated control (Fig. 2).

\section{DISCUSSION}

Cocoons of ALCM are a particularly difficult life stage of this pest to remove from and/or kill on fruit. Neither of the removal treatments (drench or high pressure washing) proved more effective with hot water than using the treatment with water at ambient temperature. In this study, fewer ALCM were removed with HPW at ambient temperature than previous research in which commercial Honiball washers removed up to $50 \%$ of cocoons. Compac rotary washers with singulated fruit removed $85-95 \%$ of cocoons

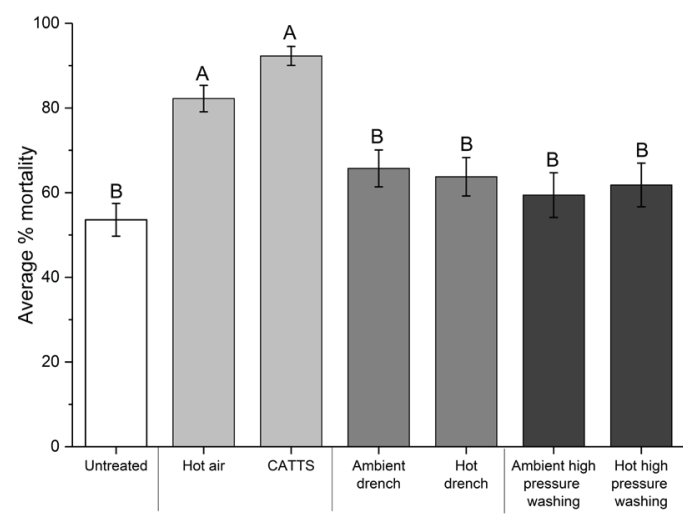

Figure 2 The mean mortality of apple leafcurling midge (Dasineura mali) cocoons after controlled atmosphere temperature treatment (CATTS), drench or high pressure washing. Vertical lines indicate the standard error of the means. Common letters above bars indicate no statistically significant difference among treatments.
(DJ Rogers, HortResearch pers. comm.; AB Woolf unpublished data). These high pressure washers were at similar pressures, pass-time, and the same apple varieties as this study. However, ALCM cocoons used in the 2008 trials were field collected, whereas those used in this trial were established under laboratory conditions and may have adhered to the fruit in a way that made them more difficult to remove. Future studies will need to be conducted to assess any difference in adhearence of field-collected vs laboratoryestablished ALCM cocoons.

Large numbers of infested fruit were required for each replicate in this trial. To provide these numbers, infested fruit were stored at $7^{\circ} \mathrm{C}$ for 2-6 months until treatment. This storage regime probably resulted in the ALCM going into diapause, an overwintering state of low metabolic activity allowing the insect to survive in a challenging environment. Clearly, diapause will be triggered in ALCM field-collected during autumn as a result of decreasing temperature and shortening days. However, a large proportion will still be at the stage before diapause or only just entering it so may not be as tolerant to extreme conditions as those kept in cold storage for a prolonged period. Therefore, higher mortality may occur following heat treatment of ALCM that had not been in coolstorage for a prolonged period of time. This hypothesis remains to be investigated; however in commercial conditions, fruit are often placed in coolstorage immediately after harvest, before processing through the packing shed and would be unlikely to be treated directly after harvest.

Of the heat treatments reported here, CATTS and hot air resulted in the greatest mortality of ALCM cocoons. This trial assessed a single CATTS protocol/treatment time, and it is unknown if changes to the treatment parameters would lead to greater ALCM control. The CATTS conditions tested here provided complete control of codling moth when tested; however, fruit quality was compromised (Jamieson et al. 2018). In Washington State, USA, fruit quality was not severely compromised after the same treatment (Neven et al. 2001). This difference may have 
been due to the diurnal heating rates and maximum temperatures experienced by the fruit on the tree before harvest, which are likely to differ between Hawke's Bay and Washington State (L Neven, pers. comm.). Therefore, further CATTS research should mimic the diurnal heating rates experienced by apples in the orchard over the month before harvest. It is hoped that an effective CATTS treatment will be developed for New Zealand apples based on acceptable fruit quality and codling-moth control. The conditions of this improved treatment should then be tested against ALCM. An alternative form of treatment using $\mathrm{X}$-rays is internationally accepted (IPPC 2009) and efficacy data already exist for codling moth. However, no $\mathrm{x}$-ray efficacy data are currently available for ALCM so further studies could be undertaken to assess this type of treatment alone and in combination with fruit washing.

Although no treatment trialled in this study resulted in complete removal or mortality of cocooned ALCM, hot air and CATTS treatments showed promise, with these treatments resulting in $82-93 \%$ mortality; however, further refinments of the CATTS parameters are required to maintain fruit quality (Jamieson et al. 2018).

\section{ACKNOWLEDGEMENTS}

The authors would like to thank New Zealand Apples \& Pears Incorporated (NZAPI) for funding this research; Richard Oliver, James Pinfold, Ian Visagie (PFR Ruakura) for engineering and programming work on the CATTS unit; Duncan Park (T\&G Hawke's Bay) for supply of apples used in this trial; Kate Colhoun and Bernie Attfield (PFR Clyde), Roger Wallis and Peter Shaw (PFR Motueka), Peter Lo and Lyn Cole (PFR Hastings), for field collection of ALCM larvae; and Manoharie Sandanayaka and Samuel Brown (PFR Auckland) for valuable comments on this manuscript.

\section{REFERENCES}

Drake SR, Moffitt HR, Fellman JK, Sell CR 1988. Apple quality as influenced by fumigation with methyl bromide. Journal of Food Science 53(6): 1710-1712.

Hawthorne AJ, Griffin MJ, Page-Weir NEM, Redpath SP, Jamieson LE 2016. Establishing cocooning apple leafcurling midge onto apples for disinfestation research. New Zealand Plant Protection 69: 328.

Honiball F, Giliomee JH, Randall JH 1979. Mechanical control of red scale (Aonidiella auranti Mask) on harvested oranges. Citrus and Subtropical Fruit Journal 549: 17-18

IPPC 2009. International Standards for Phytosanitary Measures, ISPM No. 28 Annex 6: Irradiation treatment for Cydia pomonella. Rome, IPPC, FAO.

Jamieson LE, Page-Weir NEM, Chhagan A, Olsson S, Connolly PG, McDonald RM, Woolf A 2010. High pressure water-washing to remove pests from capsicums. New Zealand Plant Protection 63: 118-122.

Jamieson LE, Wilkinson RT, Page-Weir NEM, Hawthorne AJ, Hartnett DE, Redpath SP, Chhagan A, Woolf AB, Nangul A, Guo LF. 2018. Assessing the efficacy of controlled atmosphere temperature treatment system (CATTS) against codling moth inside apples. New Zealand Plant Protection 71: 306-313.

Lowe S 1993. Apple leafcurling midge. Pipmark Technical Bulletin. New Zealand Apple and Pear Marketing Board, Palmerston North, New Zealand. 5 p.

Neven L 2005. Combined heat and controlled atmosphere quarantine treatments for control of codling moth in sweet cherries. Journal of Economic Entomology 98(3): 709-715.

Neven L, Drake S 1996. Summary of alternative quarantine treatment research in the Pacific Northwest. Annual International Research Conference on Methyl Bromide Alternatives and Emissions Reductions, 4-6 November 1997, Orlando, Florida, USA. 79 p.

Neven L, Mitcham E 1996. CATTS (Controlled Atmosphere/Temperature Treatment System): A novel tool for the development 
of quarantine treatments. American Entomologist 42(1): 56-59.

Neven L, Rehfield-Ray L 2006. Confirmation and efficacy tests against codling moth and oriental fruit moth in apples using combination heat and controlled atmosphere treatments. Journal of Economic Entomology 99(5): 1620-1627.

Neven LG, Drake SR, Shellie KC 2001. Development of a high temperature controlled atmosphere quarantine treatment for pome and stone fruits. Acta Horticulturae 553(2): 457-460.

Neven L, Rehfield-Ray L, Obenland D 2006. Confirmation and efficacy tests against codling moth and oriental fruit moth in peaches and nectarines using combination heat and controlled atmosphere treatments. Journal of Economic Entomology 99(5): 1610-1619.

Page-Weir NEM, Jamieson LE, Hawthorne AJ, Redpath SP, Chhagan A, Hartnett DE, Guo L, Woolf $A B$ 2017. Pre-treatment dips to enhance the removal of apple leafcurling midge from apples using high pressure washing. New Zealand Plant Protection 70: 315.

Shellie K, Neven, LG, Drake, SR 2001. Assessing 'Bing' sweet cherry tolerance to a heated controlled atmosphere for insect pest control. HortTechnology 11(2): 308-311.

Walker G, Morse N, Arpaia ML 1996. Evaluation of a high-pressure washer for postharvest removal of Californian red scale (Homoptera: Diaspididae). Journal of Economic Entomology 89(1): 148-155

Walker G, Zareh N, Arpaia ML 1999. Effect of pressure and dwell time on efficiency of a high-pressure washer for postharvest removal of California red scale (Homoptera: Diaspididae) from citrus fruit. Journal of Economic Entomology 92(4): 906-914. 